\title{
SOME REFLECTIONS ON THE ROLE OF CORRECTIONAL RESEARCH
}

\author{
Alfred C. Schnur* \\ I \\ INTRODUCTION
}

Laws are broken millions of times each year. As one consequence, thousands of convicted law violators are turned over to correctional agencies. For what proximate and ultimate purposes have these thousands been convicted? Just what is to be done with them? Society does not seem to know. Except for apparent satisfaction with measures short of extermination or life quarantine for most offenders, there seems to be no clear-cut agreement as to ends and means to ends. Almost all the objectives ever propounded and almost all the measures ever applied in dealing with nonconformists since the beginning of recorded time are still employed today in the management of law violators. Consequently, many different and often incompatible purposes are served, and many different and conflicting techniques are utilized.

Although society does not seem to know what it really wants, correctional agencies are, nonetheless, obliged to make decisions. Both by their action and inaction, these agencies necessarily define objectives and the means of attaining them with the resources provided and within the constraints imposed by society. Thus, albeit fortuitously, correctional agencies profoundly affect not only the convicted law violator, but free society, since virtually all convicted law violators eventually re-enter free society.

Correctional agencies have a tremendous range of discretion in their management of convicted law violators, and although they never have the benefit of society's consensus in exercising this discretion, they frequently incur its adverse criticism. Ironically, there seems to be a general unawareness that much of the confusion and inconsistency in correctional objectives and the vacillation in implementing these objectives is directly attributable to society's indecision regarding the criminal and its failure to provide the means to utilize existing knowledge or to acquire further knowledge of the variables of crime to permit optimal treatment.

II

\section{Some Limitations of Research}

As research has helped in so many other areas, so in corrections can it help to solve the problems of defining and achieving objectives in the treatment of convicted law violators. The role of correctional research, however, is fraught with possibly

*A.B. 1941, University of Pittsburgh; Ph.M. 1944, Ph.D. 1949, University of Wisconsin. Associate Professor, School of Police Administration and Public Safety, Michigan State University. Contributor to correctional periodicals. 
serious misunderstanding. It is not a panacea for correctional problems-although some correctional administrators expect it and some "researchers" claim it to be. In and of itself, it will not, for example, eliminate recidivism, nor should it be expected to do so. The correlations (and intercorrelations) of the variables of recidivism may, of course, be revealed through research, as may the conditions under which recidivism increases and decreases; but whether this knowledge, if discovered, should be used and how it should be used are matters involving values which correctional policymakers and budget-makers-not research scientists-must decide. The research scientist can help only by indicating the implications, the consequences, the costs, and the compatibility of possible decisions. In other words, research, alone, cannot actually make decisions regarding correctional means and ends; but research is the only way in which the knowledge necessary for rational decisions can be secured.

Research, too, will not always turn up manipulatable explanations for consequences. For example, previous criminal record has been found sufficiently often to pass the one-per-cent test of statistical significance to be generally accepted as one of the variables associated with recidivism. It is, however, obviously a variable about which nothing can be done, as such, in the case of a man with an extensive criminal record. This is also the case with another variable-the age at which the first crime was committed. Both of these variables represent accomplished, unalterable facts and cannot be undone. But they both constitute, along with other factors, clues of pertinence in making decisions about placement in various treatment programs and in estimating risks of recidivism, if and when the offender is released from a correctional institution.

Although objective findings disclosed by research may be unpleasant, this does not alter the fact of their existence, their consequences, or their truth. Many ideas based on these findings, however, are found "unworkable" not because of any inherent fault, but because hostile individuals tamper with the necessary conditions for their proper operation. Examples of this are often seen when, as a consequence of prison riot or other scandal, personnel representing the new penology are employed to institute reforms. Unfortunately, not all of the new staff may truly reflect the new penology, and not all of the old staff reflecting the old penology may be replaced. Those who are devotees of the old penology may busy themselves with sabotaging new ideas by failing to carry out orders, by initiating conflicting policies, and by creating situations to discredit and embarrass the new staff. By these intrusions, they may prevent the creation of the necessary conditions for the utilization of the new penology.

Research which confirms the popular is often popular; that which does not is frequently discredited on emotional grounds. For example, let us assume that research has discovered that whipping men for their misbehavior has a beneficial effect upon the recidivism rate. This conclusion would probably be accepted or rejected upon the basis of whether or not one did or did not believe in whipping, on grounds quite unrelated to its effectiveness as a correctional instrument. There would prob- 
ably be individuals who would not whip, no matter how effective it might be discovered to be, because they just did not want to whip. This, of course, would not alter the effectiveness of whipping as a corrective device.

Another source of difficulty for researchers is the desire of most laymen for definite answers, not statements of probability. Statistical analysis, however, produces only the latter. These conclusions are, nevertheless, exact in a scientific, if not a lay, sense, and they advance knowledge by enhancing the accuracy of decision-making and promoting greater understanding and control of the variables of correction. In the prediction of parole and postparole behavior, for example, although the devices produced by research leave much to be desired, they do augur the possibility of tremendous advancement, since even these inferior instruments have never failed to surpass the common-sense decisions of the men who have tried to best them.

Research is neither moral nor immoral. It is amoral. Its findings can just as easily be used to defeat as to achieve any currently-selected correctional ends. There is nothing about research, as such, that ensures that its findings will be properly understood and interpreted, or even used to serve one particular goal. As a case in point, let us consider the research that has been conducted on parole and postparole behavior. This is probably the most frequently-researched area in corrections -at least the most published. The researching of the variables of parole and postparole behavior has produced a variety of instruments that can be used-and misused-in achieving particular correctional goals-say, the minimizing of recidivism. Many of these do a sufficiently good job in forecasting to pass the one-per-cent test as well as the five-per-cent test of statistical significance. This means that correctional research has enabled such accurate forecasting of parole and postparole behavior that its explanation on the basis of luck (chance) is too remote for rational men to accept.

This knowledge can, of course, be used in widely divergent ways. A parole board can use this information to reduce the recidivism rate of parolees to a minimal level, for example, by releasing only those men who are almost certain to be successful, allowing the rest to serve out their sentences. This may, of course, increase the over-all recidivism rate of the correctional system; but it will also make the parole board and its parole supervision system appear to be very good, in one sense, because they would be dealing only with successes. This appearance, naturally, would be specious, being simply a reflection of selection (i.e., men with built-in probabilities of success, whether paroled or not) and having nothing to do with any causation that might be credited to the parole board action or parole supervision.

On the other hand, a parole board can use the same information to maximize recidivism by releasing only men who are almost certain to fail. Although such use is not probable, it could happen particularly, if, by a curious set of circumstances, there were one parole board member, or a whole parole board, who would like to discredit parole in the public eye through high failure rates.

As a third possibility, a parole board might have so much faith in parole that it 
would regard it as the only mechanism by which men should be released from prison. As a consequence, it would seek to grant parole to as many men as possible. Feeling that the public would tolerate only a certain amount of parole violation, however, it would first determine the critical point and use this and the violation rate as guides for its decisions.

To reject men for parole on the basis of their probability of success may not, incidentally, be the way to minimize the over-all recidivism rate for the whole correctional system. It may very well be the case that the man with a low probability of success on parole would have an even lower probability of success if not paroled. Since parole boards only determine the timing of one kind of release and do not usually have the power to remand men to life quarantine, since virtually all men are released at the expiration of sentences, the relevant question, if minimizing recidivism is the objective, is to determine when and how men should be released to maximize lawful behavior, and then to act accordingly.

Most parole-prediction instruments are built out of zero order correlations, without regard to intercorrelations. This could lead, through misinterpretation, to misuse. For example, the age at release has often been found to be related to success after release-the older, the better. This might result in older men being given preference in release simply because they are older. This is what could happen by using studies that have not addressed and solved the problems of intercorrelations. Such arbitrary misuse of the zero order correlations would be a gross error, since other studies that have considered intercorrelations have found that the association between age and success disappears when previous criminal record is held constant-that is, the relationship between age and recidivism is simply a reflection of previous criminal record (which, of course, may be a reflection of something else not yet included in research studies of the variables of recidivism). Too much has frequently been attributed to these zero order relationships. Until there are adequate studies conducted using more meaningful data with multiple-correlation analysis of an appropriate type, zero order relationships must be understood as being possibly no more than mere indicators of recidivism. This does not mean that such findings are not useful as selection instruments, but only that the basis for explanation and selection may be simply the score indication, and not the factor upon which the score is based.

Some of the unfounded criticisms of prediction instruments are simply a consequence of their misuse-not a fault of the instrument, but a fault of the users who drew conclusions that were not warranted. For example, some have interpreted a high success score for parole as indicating a lesser need for close supervision than a lower score. Such a high score could, however, just as well mean a high probability of success only if there is close supervision. Since studies of parole have not researched the relationship of supervision to success, it is premature to use these prediction tables as supervision guides. For all we now know, men with low success scores may have low scores because they are of the type that are likely to be oversupervised, not because they are of the type that are likely to be undersupervised. 


\section{III}

Some Possible Research Areas

The correctional process-probation, institutions, parole-is operated in relative ignorance today. The convicted law violator is subjected to this process because of his inability to adjust to the professed norms of society. The correctional worker does not know how to secure an adjustment for him, as is evidenced by the inexact estimates that have been made of the effectiveness of the correctional process. Correctional decisions are made upon the basis of blind hunch, faith, intuition, whim, dramatic circumstances, and so-called common sense, when they should be made upon the basis of the uncommon sense that emerges from a statistical analysis of data describing the offender and the process. The kind of analysis that has been successful in enabling rational decisions to be made in other areas of life cannot be made in the correctional process, however, because the research that is needed has simply not been done.

No research has been done to date that enables us either to say that one treatment program is better than another or to look at a convicted law violator and say this is the treatment he needs. There is no evidence that probation is better than institutions, that institutions are better than probation, or that parole is better than escape. (There are, for example, many dramatic instances of escapees who, having successfully reformed themselves without benefit of casework, have attained distinguished positions in their communities.) At the present time, there is no evidence that being arrested and being subjected to the correctional process aborts criminal careers or has a deterrent effect upon other potential criminals. There might even be less crime if nothing were done about it. Research could possibly shed some light, but no research conducted to date answers these questions.

Much research has been done to differentiate successful from unsuccessful probationers and successful from unsuccessful parolees. As a consequence of this research, it is possible to answer the question: How do successes differ from failures? But it is not possible, because of the way the research has been conducted, to say that the particular treatment researched is better or worse than some other program. Nor is it possible to say, now that it is known how the successes and failures differ, how the chances for success can be increased or decreased, because the factors that have been studied cannot be manipulated-they have already arranged themselves and cannot be altered in any way. In fact, in one state where prognosis is required, it is possible to make the prognosis before the convicted law violator comes to prison as accurately as if it were made the day before he left prison, because none of the experiences within the prison are taken into account in distinguishing between successes and failures. The predictive factors are things that occurred in his life before he ever came to prison and are things about which nothing can be done.

Recommendations for expensive treatment have frequently been made. Although some convicted law violators may require such treatment, it would probably be wide of the mark for many others. Instead of trying to give all convicted law viola- 
tors a little of every kind of treatment in the hope that some exposure to it will be effective, effort should rather be made to determine what treatment is best, under what conditions, and for what type of person, so that each may get enough of the kind of treatment he needs-if treatment is his need-for it to take effect. These things can be objectified and studied, if the effort is taken.

What is needed is ongoing research of a character that analyzes all the effects of all the presently available treatment techniques for all those undergoing treatment. This analysis is the only kind of analysis that will enable decision-makers to act intelligently. Such research, however, will not answer the question: What is the best thing to do with this man? It will only tell what is the best thing to do with what is now being used.

The only adequate way to ascertain the relative value of the various kinds of treatment now in operation is to take a number of offenders at the earliest point of contact before conviction, preferably at the arrest level-earlier, if there were any way of doing it-and begin scientific observations. The offenders should be closely studied, differentiated into types, and followed forward for a number of years subsequent to the cessation of any legal control over them by the state. Since sentencing practice is such a haphazard procedure at present, it is to be expected that most of the various treatment types will be represented in nearly all of the dispositions available to the court and in all of the varieties of subsequent treatment given these offenders. Such a research project should exercise no control over the management of the offender with respect to the kinds of experiences that he will have, but should rather be concerned with rigorous observation. An easy, but empty, objection to such a procedure is that by the time such research has been completed, corrections will have moved ahead and will be using new and different procedures. Although change in the correctional process is to be desired as the-years roll by, it is the observation of practitioners in the field that the Declaration of Principles, enunciated in 1870 at the first Congress of Correction in Cincinnati, has not yet been fully effected.

This analysis of the treatments which are being used at the present time should be supplemented by experimental research of treatment techniques not now being used, so that the old can be abandoned, changed, or amplified, and the new adopted, as indicated by their effectiveness as drawn from an adequate research analysis.

The lack of meaningful research regarding the merits of the various kinds of treatment constitutes an inhibiting factor in the progressive development of prison administration. Those who are dissatisfied with current prison operational methods and who feel that they should reflect our growing knowledge of human behavior in noncorrectional settings are at a loss to prove the validity of their beliefs. Conclusive evidence, one way or the other, is not currently available. The consequence is that the new penology and the old penology are discussed with heat at professional meetings, and decisions are made not upon the merits of the situation, but upon 
the basis of who is in authority and whether or not persons can be converted to a particular belief upon no more than faith.

One valuable kind of research that is gaining popularity in an analysis of the prison community as such. This subject is probably as pertinent a consideration in determining the effectiveness of a particular treatment program as is the structure of the civilian community that is trying to implement it. It is possible-even probable -that given the same personnel and program, but given divergent structures in the prison community, the success consequences of a particular program would vary. The social interactions among inmates and between inmates and civilians need further consideration in conducting treatment evaluation research.

Correctional authorities are losing much valuable material and information by not instituting parallel research evaluation programs to determine the adequacy of each new idea put into practice, for there is no other way of gauging an idea's worth. An enterprising organization would be well advised to experiment with new ideas on a small scale, with research to determine the merits of each, rather than sweepingly to overhaul its whole correctional program before the worth of the proposed innovations have been established.

Standards of evaluation with reference to other than recidivism rates are also needed. For example, the full implications of an industrial operation within an institution should be investigated to ascertain whether or not other activities could be more beneficially carried on in its stead. Thus, if it costs an institution more to manufacture an item than to purchase it on the open market, the institution might well apportion the inmate time, staff, and equipment to other activities that would be more worthwhile from a financial standpoint as well as from one of successful adjustment after release.

One of the main deficiencies of correctional research is that so many projects are conducted as though no research had been done before, as though the researcher were ignorant of previous research. The only contribution of much correctional research, therefore, is to confirm earlier research findings. This may have a disguised value, however, since certain comparisons with respect to the stability of predictive variables can then be made. But these comparisons cannot be made without serious qualification. There is some variation in the definition of what constitutes success and what constitutes failure, and enough variation in the particular factors studied, the way in which the factors are defined, the time period, and the kind of samples studied to render the results of different studies not strictly comparable. It has been observed, however, that even where the studies are sufficiently similar for comparisons to be made, certain factors are negatively related with success in one study, positively related in another, and unrelated in yet another. It has also been observed that some factors are never significantly associated with success in any study and that some factors are always related with success in every study. A useful analysis for future research would, therefore, be to compare the findings regarding particular factors and to state the limitations of the comparisons. It might be 
profitable to set up as adequate a research design as possible, with as objective definitions as possible of the variables included in these studies, with as much benefit taken of new statistical techniques as possible, to see whether such general comparisons can be confirmed. It would be more valuable if this could be done by several different investigators, in different jurisdictions, during the same time interval, in exactly the same way-and the results could then be compared.

Perhaps what is needed as much as research of the field variety is an investigation and analysis of the research that has been done-the questions that have been asked, the answers, and the associations that have been established. This would constitute a springboard for future research. At the present time, there is no place in which correctional research findings are coordinated, no easy means of referring to the findings on particular factors. The findings from correctional research today, where ascertainable, represent a veritable crazy quilt. If it were possible to map out the correctional process in all its variations and then mark the points that have been researched and the significance of the findings, there would doubtless be great embarrassment at the meager results of the characteristic sporadic ad hoc studies. If all of the correctional research that has been done could have been concentrated upon the total correctional process within one system, we would probably be in a better position than we are today with our present piecemeal knowledge. It is always true, of course, that research projects raise more questions than they answer; it is a shame, however, that the ratio of answers is so small for the field of corrections.

This is not to say, of course, that the research that has been done to this point, if utilized, would not improve correctional operations today. Some of it certainly would. In fact, this haphazard pattern has produced several interesting observations that would not have been possible had research been concentrated upon one system. Certain variables have been studied with reference to almost similar problems in many of the states of the United States and in many of the Western European countries. It is interesting to note that the association between almost similar variables and almost similar definitions of adjustment has been in the same direction, and upon occasion, the coefficients have been identical. Of course, this is something that could have happened by chance. It is quite unlikely, however (and, of course, this could be tested statistically), that essentially the same findings should have emerged in so many places by chance. Analysis may reveal certain universals for prediction systems. At least, variables would be suggested that should be included in any future project attempting to make analyses.

\section{IV}

\section{Some Obstacles to Research}

Correctional research, of course, has all the problems involved in other research in human behavior. It has, moreover, the problem of contending with the peculiar control over the research data exerted by official agencies. Correctional researchers, 
in addition to the task of resolving the problem they are addressing, also are confronted with the task of piercing the iron curtain of a certain kind of officialdom. Research really should be easier to conduct in correctional settings than elsewhere because the convicted law violators that constitute the data are controlled; but because officialdom defines the ways in which the data under control can be handled, correctional research is often made unnecessarily difficult. Much research that could have been very meaningful has been frustrated because the original research design was altered by the correctional agency-often with the explanation (excuse) that such activity would either be disturbing to the security of the institution or damaging to the treatment program of the institution.

Chief, perhaps, among the many obstacles to the acceptance of correctional research is the fact that many agencies are defensive about their work. The characterization of their efforts as ineffective or unwarranted is interpreted as a personal affront. Consequently, they resist research findings unless they accord with their preconceived notions.

Some correctional administrators, on the other hand, are interested in researchthat is, until they learn what it costs and how long it takes to secure answers. They are impatient and unwilling to pay the freight. Upon occasion, correctional administrators are so disturbed by a problem, an impending explosion, that they feel forced to turn to research for help. But then they want their answers yesterday, and they want them cheap. Research, however, cannot be tailored to meet the emotional needs of a desperate administrator. Scientific methods cannot be short-circuited. There are no bargain days for methodology.

Each classification used in preparing data constitutes a hypothesis. The validity and reliability of classifications affect the research conclusions. How reliable and valid are the classifications recorded by the correctional personnel? How much of the variation in data is to be explained by variation in the men who prepared the records, rather than by variation in the variable itself? The typical records found in correctional systems are practically useless for research purposes. They are often not worth the time and money it takes to analyze them. The lack of standards in recording is strikingly apparent when one is dealing with a recidivist with experience in several different prisons. The current prison observes him, prepares records, makes a diagnosis, and plans treatment. While much of this is in process, the current institution is awaiting the receipt of records about him from the other institutions in which he has been confined. When the various records are compared, there is so little consistency, it is often to be wondered if all these institutions were dealing with the same person. Human nature does change, but there are certain things that should remain constant from one setting to another.

Research utilizing existing records has demonstrated the inadequacy of such records not only for research purposes, but for administrative purposes. The decisions made by administrative agencies in working with these convicted law violators are at least as important as the uses made of these data for research purposes. Record- 
keeping systems need tremendous overhauling to serve either administrative or research purposes. Possibly many of the erroneous common-sense generalizations made by men of experience are reflections of not just faulty thinking or the impossibility of analyzing a large number of variables mentally, but also the inadequacy of the data from which the common-sense observations are drawn.

Among the many inadequacies of correctional agency record data is the sheer absence of information. Often, when analyzing a case record, it is impossible to ascertain whether the reason for missing data is that the question was not asked, the question was inapplicable, or no information was available. The reasons for the absence of data, as well as the fact of its absence, are pertinent to research analysis. Researchers require assurance that the same questions were applied to all the cases. When there is no information in the record, there is an area of doubt.

Conclusions drawn from case studies merely represent a lower and more haphazard form of statistical analysis. Case studies of adequate quality are useful as a basis for designing a quantitative assessment of a problem. Often, however, case studies are not useful because persons making them are not sufficiently rigid and objective in securing data. Case studies that are not good enough for statistical processing really are not good enough for any kind of generalizing. Data that can be defined can be communicated and thereby be made publicly accessible. Such data can be analyzed. Data that is only privately accessible and cannot be defined cannot be made a basis for drawing reliable conclusions. Case studies tend to be interpreted according to the bias and training of the observer and not according to the data. It is very easy to find what one chooses to find in case studies. This does not mean, of course, that case studies should not be carried out; they should be carried out, however, only as a preliminary to statistical analysis.

Much statistical research has had little significance because some people have been so eager to apply formulae to problems that they have not taken sufficient time to make a qualitative study of the problem. Time should be taken for study before developing formulae. Too often, many things are learned about a problem after the project has begun and it is too late to change the research design and start over; and many ideas of this type are never followed up because so many correctional research projects are one-shot efforts.

\section{V}

\section{Some Caveats and Conclusions}

Some correctional agencies are reluctant to sanction research because of the many unqualified comparisons made of the success rates reported by research in various jurisdictions and the widespread conclusion that the success rate is an adequate indication of the relative worth of correctional agencies. Such comparisons, of course, are often unwarranted because success rates are affected by many variables that have nothing to do with the competence of personnel or the adequacy of the agency's program. Variations in success rates among different jurisdictions as re- 
ported by different researchers may simply be reflections of differences in the definition of success in the different studies, or differences in the adequacy of the data collected. Some studies have definitions of success so strict that if they were applied to the average man on the street, he would probably be classified as a failure. Other studies classify a man as a success if he has not been convicted of a crime subsequent to his release from the treatment program. If two jurisdictions were compared on success rates alone, the jurisdiction that had the researcher with the more rigorous definition would probably have a lower success rate than the one with the less stringent definition, even if the former had the better program. This would be even more probable if the researcher with the more rigorous definition of success also had intensively investigated to see if the men were successful and the researcher with the less stringent definition relied solely upon the law enforcment records for his information. Differences in success rates may be more a reflection of differences in the definitions and in the thoroughness of research than a reflection of the relative effectiveness of various agencies in minimizing recidivism.

Ranking agencies in effectiveness on the basis of success rates may not even be warranted when the researches are conducted with the same definitions and the same thoroughness. This could be the case if some agencies had more offenders who were difficult-treatment types than the others had. This might affect success rates more than variations in quality of treatment. To compare agency effectiveness in various jurisdictions, it would really be necessary that the persons undergoing treatment in the various jurisdictions be social twins with respect to factors pertinent to success and failure. The treatment itself should be the only variable.

Total success rates reveal very little. What kind of people were these successes and failures to start with? For example, the higher or lower success rate of one probation department when compared with another may merely reflect a difference in judicial sentencing practice. One probation department may appear to be more successful simply because one judge was more cautious than another in granting probation. Possibly the more cautious and selective the judge, the higher the total success rate will be. Similarly, the probation department that operates in a community with a strict police department is more likely to have a case load with a large proportion of less serious offenders than the probation department that operates in a community with lax law enforcement. Consequently, cases of the former will have higher built-in probabilities of success-i.e., they will be more likely to be successes, no matter what kind of supervision they are given on probation.

Research reports should include a detailed description of the program that has been studied and of the setting in which it operated. This increases the value of the report and facilitates fairer comparisons of similar programs operated by different agencies. Too often, it is assumed that if programs have the same name, they are the same. Some correctional systems have programs in name only, and others have welldeveloped programs. A detailed description of just what the program is makes it possible for findings to be interpreted more meaningfully. 
Despite the confusion of means and ends that characterizes corrections, research can be conducted that can facilitate the formulation of more rational decisions in the management of law violators. Although much more is needed and many problems in its conduct and the utilization of its findings are yet to be solved, completed correctional research has unquestionably advanced the understanding, prediction, and control of the variables of recidivism and has helped in the determination and the achievement of correctional goals. 
